\title{
ANALISIS JARINGAN WLAN 802.11g RUMAH SAKIT KAPAL KABUPATEN BADUNG
}

\author{
IGN. Agung Dwi Jaya Putra ${ }^{1}$, D.M. Wiharta ${ }^{2}$, N.P. Sastra ${ }^{3}$ \\ Program Studi Teknik Elektro, Fakultas Teknik, Universitas Udayana \\ Email : \\ gungjayadocument@gmail.com ${ }^{1}$, wiharta@unud.ac.id ${ }^{2}$, putra.sastra@unud.ac.id ${ }^{3}$
}

\begin{abstract}
ABSTRAK
Untuk pengujian secara langsung adakalanya signal level dari access point tidak selalu dapat mencakup jarak jangkauan yang maksimal. Disebabkan sinyal dari access point akan mengalami propagasi yang mengakibatkan sinyal mengalami penurunan atau pelemahan level sinyal. Berbagai macam faktor dapat memengaruhi perambatan gelombang sinyal dalam ruangan, seperti pemantulan, pembelokkan, maupun penghamburan sinyal. Pada gedung $B$ Rumah Sakit Kapal Kabupaten Badung dilakukan analisis mengenai Jaringan WLAN 802.11g untuk mengetahui karakteristik kualitas level sinyal dan QoS. Terbagi menjadi 2 model pengukuran yaitu tanpa penghalang dan penghalang dinding. Hasil dari pengukuran level sinyal tertinggi mencapai -49 dBm sedangkan untuk signal level terendah mencapai -88 dBm. Kemudian untuk hasil pengukuran throughput, diperoleh maksimal hingga mencapai 4,8 Mbps, dari maksimal bandwidth yang telah tersedia yaitu $10 \mathrm{Mbps}$,untuk nilai packet loss tidak lebih dari 3\%, untuk nilai jitter 0,04 ms dan nilai delay tidak lebih dari $100 \mathrm{~ms}$. Sedangkan untuk coverage area berdasarkan pengujian menggunakan software menyesuaikan denah pada gedung, hampir sesuai dengan hasil perhitungan signal level.
\end{abstract}

Kata Kunci : Propagasi indoor, QoS, Signal level, WLAN 802.11g,

\section{ABSTRACK}

For direct testing sometimes the signal level of the access point cannot always cover the maximum range of distance due to signal wave propagation in the room, such as reflection, alteration, or scattering of signals. For the purpose of implementation optimization, this study aims to obtain characteristics of signal level quality and QoS at the Mangusada Hospital of Badung Regency. The indoor propagation analysis of WLAN IEEE 802.11g is based on 3 models of measurement ie without barrier, wall barrier, and floor barrier. The result of the highest signal level measurement is $-49 \mathrm{dBm}$, while the lowest signal level is -88 $\mathrm{dBm}$. Maximum throughput measurement results $8.05 \mathrm{Mbps}$, from the maximum available bandwidth of $10 \mathrm{Mbps}$. While the coverage area based on testers using the software to adjust the floor plan on the building, almost in accordance with the calculation of signal level.

Keywords : Propagation indoor, QoS, Signal level, WLAN 802.11g.

\section{PENDAHULUAN}

Wireless LAN merupakan teknologi jaringan nirkabel yang dapat digunakan untuk komunikasi suara maupun data. Wireless LAN berkembang dengan pesat karena teknologi ini relatif murah dan mudah diimplementasikan. Standar untuk Wireless LAN ini dibuat oleh Grup IEEE (Institute of Electrical and Electronics Engineer. Grup IEEE inilah yang menetapkan standar-standar wireless yang disebut juga standar IEEE802.11.[1]
Pada penelitian sebelumnya dilakukan pengukuran propagasi indoor dan throughput yang dimana parameternya WLAN 802.11g, perhitungan dan pengukuran signal level dan throughput, Penelitian itu mengambil kasus di Diskominfo Kabupaten Badung.[2]

Dari paparan penelitian yang telah dilakukan sebelumnya, maka ada penambahan beberapa parameter untuk pengukuran Qos (Quality Of Service) yang dimana pengukuran tersebut mengukur 
tentang Delay,Packet Loss,Jitter dan Throughput

Untuk itu Rumah Sakit Kapal sebagai penyedia layanan kesehatan sebaiknya memiliki layanan telekomunikasi yang memadai sehingga konsumen dapat menikmati layanan Wi-Fi di Rumah Sakit Kapal. Pada Rumah Sakit Kabupaten Badung khususnya gedung B sudah diterapkannya jaringan WLAN.

\section{KAJIAN PUSTAKA}

\subsection{WLAN IEEE 802.11g}

Wireless LAN merupakan local area network yang menghubungkan dua komputer atau lebih tanpa menggunakan kabel. WLAN memanfaatkan teknologi modulasi spread spectrum berdasarkan gelombang radio sebagai media transmisi untuk dapat berkomunikasi antara device pada area yang terbatas, atau dapat disebut sebagai basic servive set. Hal ini memberikan setiap pengguna suatu mobilitas untuk dapat bergerak di dalam cakupan yang luas dan tetap terhubung pada suatu jaringan [2].

Standar IEEE 802.11g merupakan standar wireless local area network (WLAN) yang dapat meningkatkan performansi, dimana standar ini bekerja pada frekuensi 2,4 GHz. Sedangkan untuk receiver sensitivity pada standar WLAN 802.11g, standar ini memiliki sensitivitas penerima sekitar $-88 \mathrm{dBm}$ untuk minimum data rate 6 Mbps dan $-68 \mathrm{dBm}$ untuk maksimum data rate $54 \mathrm{Mbps}$ [3].

\subsection{Propagasi Indoor}

Dalam komunikasi wireless, adanya media transmisi yaitu gelombang radio. Gelombang radio akan melakukan propagasi untuk mentransmisikan suatu informasi. Propagasi radio didefinikasikan sebagai perambatan gelombang radio di suatu medium yang pada umumnya adalah udara. Propagasi gelombang radio dapat dikatakan ideal jika gelombang yang dipancarkan oleh antena pemancar diterima langsung oleh antena penerima tanpa melalui suatu hambatan. Pada propagasi indoor terdapat 3 pemodelan yaitu tanpa penghalang, dengan penghalang dinding, dan dengan penghalang lantai [4].
Untuk pemodelan tanpa penghalang, menggunakan persamaan received signal level sebagai berikut.

$R S L=E I R P-L+G r$

Dimana :

$R S L=$ Level kuat sinyal yang diterima (dBm)

$E I R P=$ Energi yang dikeluarkan oleh sebuah access point atau pemancar $(\mathrm{dBm})$

$L \quad=$ Loss $(\mathrm{dB})$

$\mathrm{Gr}=$ Penguat pada penerima $(\mathrm{dB})$

Untuk menghitung EIRP, persamaan yang digunakan adalah sebagai berikut.

$E I R P=T_{x}+G_{t}-L_{f}$

Dimana :

$T_{x}=$ Transmit power $(\mathrm{dBm})$

$G_{t}=$ Gain antenna (dBi)

$L_{f}=$ Loss fedder (dB)

Untuk mencari nilai Loss digunakan persamaan berikut.

$L_{(C)}=L_{O}+10 n \log (d)$

Dimana :

$L_{O}=$ Nilai konstanta untuk frekuensi 2,45 GHz (40,2 dB)

$n=$ Nilai path loss eksponen konstanta untuk frekuensi 2,45 GHz $(4,2)$

$d \quad=\operatorname{Jarak}(\mathrm{m})$

Untuk pemodelan penghalang dinding, menggunakan persamaan berikut [4].

$P_{r}=P_{t} G_{t} G_{r}\left(\frac{\lambda}{4 \pi}\right)^{2} d^{-\alpha} 10^{\frac{x \varphi}{10}} \prod_{\mathrm{m}=1}^{\mathrm{M}}\left|\Gamma_{\mathrm{m}}\right|^{2}$

Dimana :

$P_{r} \quad=$ Received signal level (watt)

$P_{t} \quad=$ Power transmit bernilai 20

$\mathrm{dBm}$ (berdasarkan tabel 1)

$G_{t} \quad=$ Transmit antenna gain bernilai $3 \mathrm{~dB}$ (berdasarkan tabel 1)

$G_{r} \quad=$ Receive antenna gain bernilai $3 \mathrm{~dB}$ (berdasarkan tabel 1)

$\left(\frac{\lambda}{4 \pi}\right)=$ Panjang gelombang $\left({ }^{c} / f\right)$

$d^{-\alpha}=$ Jarak dari pemancar ke penerima $(\mathrm{m})$

$10^{\frac{x \varphi}{10}} \quad=$ Nilai Shadowing 
$\begin{aligned} \prod_{\mathrm{m}=1}^{\mathrm{M}}\left|\Gamma_{\mathrm{m}}\right|^{2}= & \text { Nilai transmisi koefisien } \\ & \begin{array}{l}\text { dinding }(0,3) \text { dan jumlah } \\ \text { dinding }\end{array}\end{aligned}$

Sedangkan untuk pemodelan penghalang lantai hampir sama dengan pemodelan penghalang dinding, perbedaannya pada nilai transmisi koefisien, dimana bernilai 0,17.

$P_{r}=P_{t} G_{t} G_{r}\left(\frac{\lambda}{4 \pi}\right)^{2} d^{-\alpha} 10^{\frac{x \varphi}{10}} \prod_{\mathrm{n}=1}^{\mathrm{N}}\left|\Gamma_{\mathrm{n}}\right|^{2}$

\subsection{QoS (Quality Of Service)}

Qos adalah kemampuan suatu jaringan untuk menyediakan layanan yang baik dengan menyediakan bandwidth, mengatasi jitter dan delay. Parameter QoS adalah Jitter, packet loss, Throughput, Delay. [5]

QoS sangat ditentukan oleh kualitas jaringan yang digunakan. Terdapat beberapa faktor yang dapat menurunkan nilai QoS seperti: redaman, distorsi, dan noise.

\subsection{Perangkat Access Point Ubiquiti Unifi}

Access point merupakan perangkat yang menjadi sentral koneksi dari user ke ISP. Access point berfungsi mengkonversikan sinyal frekuensi radio (RF) menjadi sinyal digital yang akan disalurkan melalui kabel, atau disalurkan ke perangkat WLAN yang lain dengan cara dikonversikan ulang menjadi sinyal frekuensi radio.

Spesifikasi dari access point Ubiquiti Unifi dapat dilihat pada Tabel 1 berikut.

Tabel 1 Spesifikasi Ubiquiti Unifi [7]

\begin{tabular}{|c|c|}
\hline Dimension & $20 \times 20 \times 3.65 \mathrm{~cm}$ \\
\hline Weight & $\begin{array}{r}290 \mathrm{~g}(430 \mathrm{~g} \text { with } \\
\text { mounting kit) }\end{array}$ \\
\hline Ports & $\begin{array}{r}\text { Ethernet (Auto MDX, } \\
\text { autosensing } \\
10 / 100 \mathrm{Mbps})\end{array}$ \\
\hline Range & $122 \mathrm{~m}(400 \mathrm{ft})$ \\
\hline Buttons & Reset \\
\hline Antennas & $\begin{array}{r}3 \text { dBi Omni (supports } \\
2 \times 2 M I M O \text { with spatial } \\
\text { diversity) }\end{array}$ \\
\hline Wi-FI Standards & $802.11 \mathrm{~b} / \mathrm{g} / \mathrm{n}$ \\
\hline Power Method & $\begin{array}{l}\text { Passive Power over } \\
\text { Ethernet }(12-24 \mathrm{~V})\end{array}$ \\
\hline Power Supply & $\begin{array}{r}24 \mathrm{~V} 0.5 \mathrm{~A} \text { PoE Adapter } \\
\text { included }\end{array}$ \\
\hline $\begin{array}{l}\text { Maximum Power } \\
\text { Consumption }\end{array}$ & $4 W$ \\
\hline Max Tx Power & $20 \mathrm{dBm}$ \\
\hline$B S S I D$ & Up to four per radio \\
\hline Power Save & Supported \\
\hline Wireless Security & WEP, WPA-PSK, WPA \\
\hline
\end{tabular}

\begin{tabular}{|c|c|}
\hline & $\begin{array}{r}-T K I P, W P A 2 \text { AES, } \\
802.11 i\end{array}$ \\
\hline Certification & $C E, F C C, I C$ \\
\hline Mounting & $\begin{array}{l}\text { Wall/ Ceiling (Kits } \\
\text { included) }\end{array}$ \\
\hline Operating Temperature & -10 to $70^{\circ} \mathrm{C}\left(14\right.$ to $158^{\circ}$ \\
\hline Operating Humidity & 5-80\% Noncondensing \\
\hline
\end{tabular}

\section{METODE PENELITIAN}

Analisis dalam penelitian ini dilakukan dalam beberapa tahapan berikut ini.

a. Melakukan perhitungan signal level dimana pada pemodelan tanpa penghalang dan penghalang dinding.

b. Melakukan pengukuran signal level berdasarkan jarak antara client dan AP dengan menggunakan kondisi yang sama dengan pengukuran signal level.

c. Melakukan analisis antara pengukuran signal level dengan teori yang digunakan disertai dengan grafik pendukung.

d. Pengukuran QoS pada setiap lantainya.

e. Pengukuran coverage dengan metode walktest berdasarkan titik pengukuran signal level.

\section{HASIL DAN PEMBAHASAN}

\subsection{Hasil Penelitian}

Perhitungan dan Pengukuran mempergunakan salah satu lantai pada gedung B Rumah Sakit Kapal yang dianggap mewakili semua pemodelan propagasi indoor.

\subsubsection{Pengukuran Signal Level kondisi tanpa penghalang, penghalang 1 dinding dan penghalang 2 dinding.}

Hasil dari Pengukuran Signal Level kondisi tanpa penghalang dapat dilihat pada table 2 dimana nilai signal level terkecil yaitu pada titik 12 dan tertinggi pada titik 5 .

Tabel 2 Pengukuran signal level kondisi tanpa penghalang

\begin{tabular}{|c|c|c|}
\hline Titik & $\begin{array}{c}\text { Jarak Antara } \\
\text { AP dan Client } \\
\text { (m) }\end{array}$ & $\begin{array}{c}\text { Hasil } \\
\text { Pengukuran } \\
\text { (dBm) }\end{array}$ \\
\hline 1 & 9,13 & -64 \\
\hline 2 & 7,31 & -62 \\
\hline 3 & 5,4 & -50 \\
\hline 4 & 3,9 & -51 \\
\hline 5 & 3,9 & -49 \\
\hline 6 & 5,4 & -52 \\
\hline
\end{tabular}




\begin{tabular}{|c|c|c|}
\hline 7 & 8,1 & -66 \\
\hline 8 & 11,1 & -77 \\
\hline 9 & 13,8 & -79 \\
\hline 10 & 15,3 & -83 \\
\hline 11 & 19,2 & -86 \\
\hline 12 & 19,2 & -88 \\
\hline 13 & 15,3 & -82 \\
\hline 14 & 13,8 & -80 \\
\hline 15 & 11,1 & -78 \\
\hline 16 & 8,1 & -67 \\
\hline
\end{tabular}

Untuk Hasil dari Pengukuran Signal Level kondisi penghalang 1 dinding dapat dilihat pada tabel 3 dimana nilai signal level terkecil yaitu pada Ruang R2 dan tertinggi pada Ruang R1.

Tabel 3 Pengukuran signal level kondisi penghalang 1 dinding.

\begin{tabular}{|c|c|c|c|}
\hline \multirow{4}{*}{$\begin{array}{c}\text { Rua } \\
\text { ng }\end{array}$} & $\begin{array}{c}\text { Nilai } \\
\text { Shadowing }\end{array}$ & $\begin{array}{c}\text { Jarak } \\
\text { Antara } \\
\text { AP dan } \\
\text { Client } \\
\text { (m) }\end{array}$ & $\begin{array}{c}\text { Hasil } \\
\text { Pengukuran } \\
\text { (dBm) }\end{array}$ \\
\hline \multirow{4}{*}{ R1 } & 1,4193 & 4,17 & -44 \\
\cline { 2 - 4 } & 3,3014 & 5,67 & -47 \\
\cline { 2 - 4 } & 4,3541 & 7,17 & -51 \\
\cline { 2 - 4 } & 1,7533 & 8,67 & -66 \\
\hline R2 & 1,2307 & 25,3 & -67 \\
\cline { 2 - 4 } & 2,3435 & 26,8 & -69 \\
\hline \multirow{2}{*}{ R3 } & 1,3263 & 4,9 & -45 \\
\hline R4 & 1,2500 & 18,7 & -53 \\
\hline R5 & 10,2831 & 21,5 & -56 \\
\hline
\end{tabular}

Untuk hasil Pengukuran Signal Level kondisi penghalang 2 dinding dapat dilihat pada table 4 dimana nilai signal level terkecil yaitu pada Ruang R4 dan tertinggi pada Ruang R3.

Tabel 4 Perhitungan dan pengukuran signal level kondisi penghalang 2 dinding.

\begin{tabular}{|c|c|c|c|}
\hline $\begin{array}{c}\text { Rua } \\
\text { ng }\end{array}$ & $\begin{array}{c}\text { Nilai } \\
\text { Shadowin } \\
\mathbf{g}\end{array}$ & $\begin{array}{c}\text { Jarak } \\
\text { Antara AP } \\
\text { dan Client } \\
\mathbf{( m )}\end{array}$ & $\begin{array}{c}\text { Hasil } \\
\text { Pengukuran } \\
\text { (dBm) }\end{array}$ \\
\hline R1 & 1,4193 & 11,5 & -60 \\
\hline R2 & 3,3014 & 13 & -62 \\
\hline R3 & 4,3541 & 14,5 & -61 \\
\cline { 2 - 4 } & 1,7533 & 16 & -55 \\
\cline { 2 - 4 } & 1,2307 & 17,5 & -59 \\
\hline R4 & 2,3435 & 19 & -61 \\
\cline { 2 - 4 } & 1,3263 & 20,5 & -69 \\
\hline
\end{tabular}

\subsubsection{Pengukuran QoS ( Quality Of Service )}

Pada pengukuran QoS (Quality Of Service) menggunakan software Axence NetTools pada perangkat client. Berikut adalah hasil pengukuran Qos dengan parameter Delay, Throughput, Jitter, Packet Loss.

Untuk hasil pengukuran Quality Of Service Delay sudah termasuk dalam katerogori Sangat Bagus itu dapat dilihat pada Tabel 5.

Tabel 5 Hasil pengukuran Qos (Quality Of Service) Delay

\begin{tabular}{|l|c|c|c|l|}
\hline \multicolumn{1}{|c|}{ Situs } & $\begin{array}{c}\text { Averag } \\
e(\mathrm{~ms})\end{array}$ & $\begin{array}{c}\text { Min } \\
(\mathrm{ms})\end{array}$ & $\begin{array}{c}\text { Max } \\
(\mathrm{ms})\end{array}$ & $\begin{array}{l}\text { TIPHO } \\
\mathrm{N}\end{array}$ \\
\hline $\begin{array}{l}\text { www.yout } \\
\text { ube.com }\end{array}$ & 46,5 & 35,5 & 236 & $\begin{array}{l}\text { Sangat } \\
\text { Bagus }\end{array}$ \\
\hline $\begin{array}{l}\text { www.goog } \\
\text { le.com }\end{array}$ & 66 & 35,25 & 295,5 & $\begin{array}{l}\text { Sangat } \\
\text { Bagus }\end{array}$ \\
\hline $\begin{array}{l}\text { www.kom } \\
\text { pas.com }\end{array}$ & 52,75 & 21,75 & 451,5 & $\begin{array}{l}\text { Sangat } \\
\text { Bagus }\end{array}$ \\
\hline $\begin{array}{l}\text { www.face } \\
\text { book.com }\end{array}$ & 56,25 & 32,5 & 269,75 & $\begin{array}{l}\text { Sangat } \\
\text { Bagus }\end{array}$ \\
\hline $\begin{array}{l}\text { www.blog } \\
\text { spot.com }\end{array}$ & 42,5 & 33 & 189 & $\begin{array}{l}\text { Sangat } \\
\text { Bagus }\end{array}$ \\
\hline
\end{tabular}

Untuk hasil pengukuran Quality Of Service Packet Loss sudah termasuk dalam katerogori Sangat Bagus itu dapat dilihat pada Tabel 6 .

Tabel 6 Hasil pengukuran Qos (Quality Of Service) Packet Loss.

\begin{tabular}{|c|c|c|c|c|}
\hline \multirow{2}{*}{\begin{tabular}{c} 
NNS \\
\cline { 2 - 4 } \\
\cline { 2 - 4 } \\
ube.com
\end{tabular}} & \multicolumn{3}{|c|}{ Packet } & TIPHO \\
\hline $\begin{array}{c}\text { www.goog } \\
\text { le.com }\end{array}$ & 250 & 0,75 & 0 & $\begin{array}{c}\text { Sangat } \\
\text { Bagus }\end{array}$ \\
\hline $\begin{array}{c}\text { www.kom } \\
\text { pas.com }\end{array}$ & 250 & 3,75 & 1,5 & $\begin{array}{c}\text { Sangat } \\
\text { Bagus }\end{array}$ \\
\hline $\begin{array}{c}\text { www.face } \\
\text { book.com }\end{array}$ & 250 & 2,5 & 1 & $\begin{array}{c}\text { Sangat } \\
\text { Bagus }\end{array}$ \\
\hline $\begin{array}{c}\text { www.blogs } \\
\text { pot.com }\end{array}$ & 250 & 1,75 & 0,75 & $\begin{array}{c}\text { Sangat } \\
\text { Bagus }\end{array}$ \\
\hline
\end{tabular}

Untuk hasil pengukuran Quality of Service Throughput tiap lantainya itu dapat dilihat pada Tabel 7 . 
Tabel 7 Hasil pengukuran Qos (Quality Of Service) Throughput.

\begin{tabular}{|c|c|c|c|c|}
\hline Gedung & $\begin{array}{c}\text { La } \\
\text { nta }\end{array}$ & \multicolumn{3}{|c|}{ Troughput } \\
\cline { 3 - 5 } & $\mathrm{i}$ & $\begin{array}{c}\text { Average } \\
\text { (Mbps) }\end{array}$ & $\begin{array}{c}\text { Maksimu } \\
\mathrm{m} \text { (Mbps) }\end{array}$ & $\begin{array}{c}\text { Minimu } \\
\mathrm{m} \\
(\mathrm{Mbps})\end{array}$ \\
\hline \multirow{3}{*}{$\begin{array}{c}\text { Gedung } \\
\text { B }\end{array}$} & 1 & 3,19 & 7,51 & 0,03 \\
\cline { 2 - 5 } & 2 & 5,64 & 9,41 & 0,02 \\
\cline { 2 - 5 } & 3 & 4,56 & 7,50 & 0,02 \\
\cline { 2 - 5 } & 4 & 5,60 & 8,09 & 0,07 \\
\hline
\end{tabular}

Untuk hasil pengukuran Quality Of Service Jitter dengan interval 0.0 sampai dengan 15.0 itu dapat dilihat pada Tabel 8.

Tabel 8 Hasil pengukuran Qos (Quality Of Service) Jitter

\begin{tabular}{|c|c|c|c|}
\hline Interval & $\begin{array}{c}\text { Transfer } \\
(\mathrm{MBps})\end{array}$ & $\begin{array}{c}\text { Bandwidth } \\
(\mathrm{Mbps})\end{array}$ & Jitter (ms) \\
\hline $0.0-1.0$ & 1,08 & 9,04 & 0,028 \\
\hline $1.0-2.0$ & 1,20 & 10,0 & 0,038 \\
\hline $2.0-3.0$ & 1,19 & 9,97 & 0,041 \\
\hline $3.0-4.0$ & 1,20 & 10,0 & 0,041 \\
\hline $4.0-5.0$ & 1,19 & 9,96 & 0,042 \\
\hline $5.0-6.0$ & 1,20 & 10,0 & 0,042 \\
\hline $6.0-7.0$ & 1,20 & 10,0 & 0,037 \\
\hline $7.0-8.0$ & 1,19 & 9,96 & 0,043 \\
\hline $8.0-9.0$ & 1,20 & 9,99 & 0,038 \\
\hline $9.0-10.0$ & 1,19 & 10,0 & 0,039 \\
\hline $10.0-11.0$ & 1,20 & 10,0 & 0,045 \\
\hline $11.0-12.0$ & 1,20 & 10,0 & 0,043 \\
\hline $12.0-13.0$ & 1,19 & 9,95 & 0,053 \\
\hline $13.0-14.0$ & 1,20 & 10,0 & 0,038 \\
\hline $14.0-15.0$ & 1,19 & 9,97 & 0,043 \\
\hline $15.0-15.0$ & 0,04 & 131 & 0,043 \\
\hline
\end{tabular}

Berdasarkan Tabel 8,9,10 dan 11 terlihat hasil pengukuran QoS yang dimana dapat dikatan sangat bagus, karena dari pengukuran didapatkan hasil yang sangat bagus menurut standar TIPHON.

\subsubsection{Pengukuran Coverage Area}

Berdasarkan pengukuran dari signal level, pengukuran coverage bertujuan untuk mengetahui coverage maksimum dari AP yang berada pada gedung $B$ Rumah Sakit Kapal. Menggunakan software Ekahau HeatMapper sebagai media untuk mengukur coverage area pada gedung $B$.

Berikut adalah kualitas coverage berdasarkan warna dalam software Ekahau HeatMapper yang dapat dilihat pada Tabel 9.

Tabel 9 Kuat sinyal coverage area wireless pada software Ekahau HeatMapper [8].

\begin{tabular}{|c|c|c|}
\hline $\begin{array}{c}\text { Warna } \\
\text { coverage }\end{array}$ & $\begin{array}{c}\text { Kuat sinyal } \\
(\mathrm{dBm})\end{array}$ & $\begin{array}{c}\text { Kualitas } \\
\text { sinyal }\end{array}$ \\
\hline & $-40 \mathrm{~s} / \mathrm{d}-50$ & Baik \\
\hline & $-50 \mathrm{~s} / \mathrm{d}-60$ & $\begin{array}{c}\text { Kurang } \\
\text { baik }\end{array}$ \\
\hline & $-60 \mathrm{~s} / \mathrm{d}-85$ & Kurang \\
\hline & $-85 \mathrm{~s} / \mathrm{d}-100$ & Buruk \\
\hline
\end{tabular}

Berikut ini hasil pengukuran coverage area pada Gambar 4.

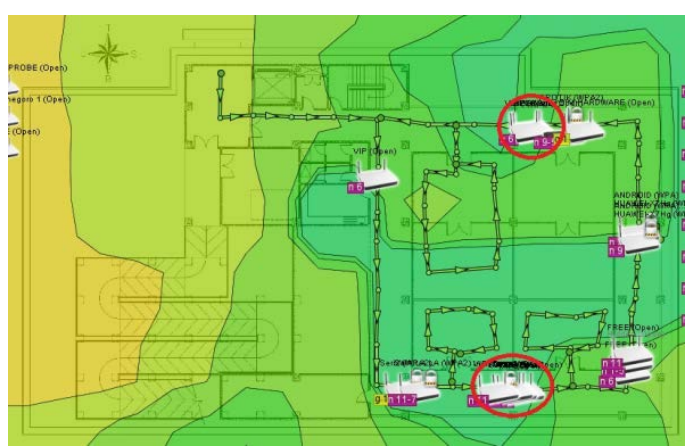

Gambar 4 Hasil pengukuran coverage

Terlihat area yang ter-cover sinyal wifi sudah mencakup seluruh ruangan pada lantai 4 gedung $\mathrm{B}$ dan dapat dikatan baik.

\subsection{PEMBAHASAN}

\subsubsection{Perhitungan permodelan kondisi tanpa penghalang, penghalang 1 dinding dan penghalang 2 dinding.}

Pada pemodelan tanpa penghalang menggunakan persamaan (1). Terlebih dahulu mencari nilai Loss dengan persamaan (3) berikut penjabarannya.

$L_{(C)}=L_{O}+10 n \log (d)$

$L_{(C)}=40,2+10.4,2 \log (19,2)$

$L_{(C)}=94,0 d B$

Setelah itu mencari nilai EIRP menggunakan persamaan (2) sesuai dengan Tabel 1, berikut penjabarannya.
$E I R P=T_{x}+G_{t}-L_{f}$
$E I R P=20+3-0$
$E I R P=23 \mathrm{dBm}$

Dilanjutkan mencari nilai dari signal level menggunakan persamaan (1).

$R S L=E I R P-L+G r$ 


$$
\begin{aligned}
R S L & =23-94,0+3 \\
R S L & =-68 \mathrm{dBm}
\end{aligned}
$$

Selanjutnya untuk perhitungan pemodelan penghalang dinding menggunakan persamaan (4) berikut penjabarannya.

$P_{r}=P_{t} G_{t} G_{r}\left(\frac{\lambda}{4 \pi}\right)^{2} d^{-\alpha} 10^{\frac{x \varphi}{10}} \prod_{\mathrm{m}=1}^{\mathrm{M}}\left|\Gamma_{\mathrm{m}}\right|^{2}$

$P_{r}=4.3 .3\left(\frac{3.10^{8} / 2,4.10^{9}}{4.3,14}\right)^{2} 4,17^{-2} \cdot 1,4193|0,3|^{2}$

$P_{r}=4 \cdot 3 \cdot 3 \cdot 9,904 \times 10^{-5} \cdot 4,17^{-2} \cdot 1,4193 \cdot 0,09$

$P_{r}=2,61596 \cdot 10^{-5} \mathrm{~W}=-75,82 \mathrm{dBm}$

Seluruh hasil perhitungan dengan kondisi pemodelan propagasi indoor dapat dilihat pada Gambar 2, Gambar 3, dan Gambar 4 berikut.

\subsubsection{Perbandingan Perhitungan dan Pengukuran Signal Level}

Perhitungan dan Pengukuran selanjutnya akan ditampilkan pada grafik. Untuk perbandingan grafik pengukuran dan perhitungan signal level kondisi tanpa penghalang dinding dapat dilihat pada gambar 1.

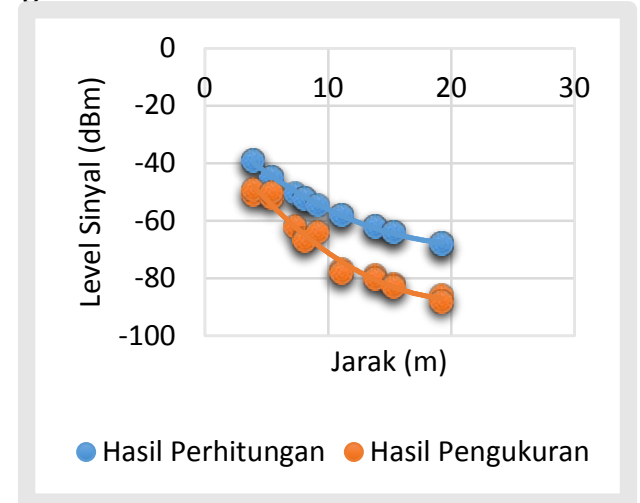

Gambar 1 Grafik Perbandingan perhitungan dan pengukuran signal level kondisi tanpa penghalang

Untuk perbandingan grafik pengukuran dan perhitungan signal level kondisi penghalang 1 dinding dapat dilihat pada gambar 2 .

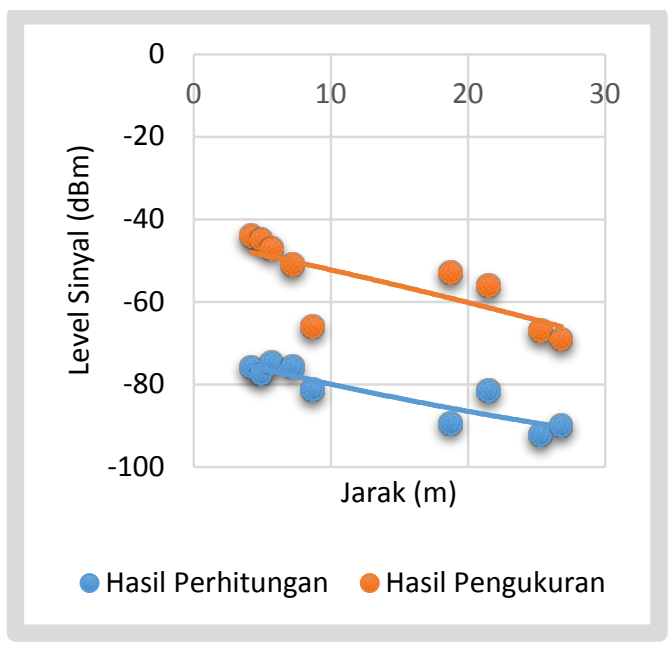

Gambar 2 Grafik Perbandingan perhitungan dan pengukuran signal level kondisi penghalang 1 dinding

Untuk perbandingan grafik pengukuran dan perhitungan signal level kondisi penghalang 2 dinding dapat dilihat pada gambar 3.

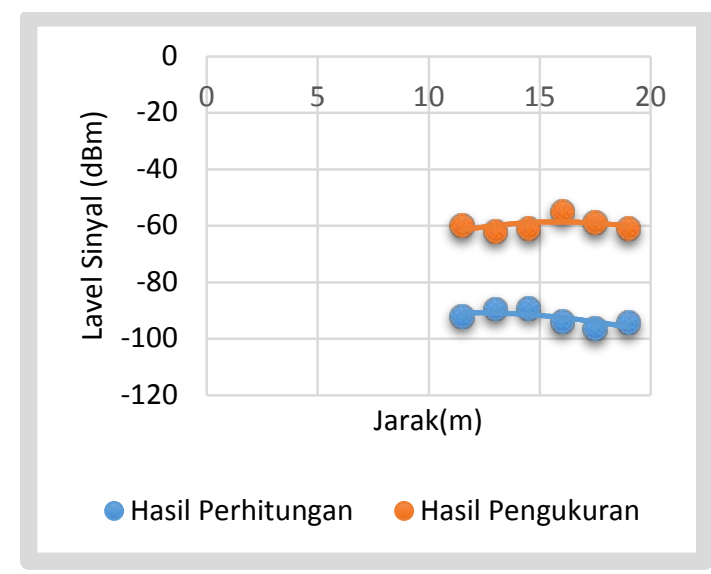

Gambar 3 Grafik perbandingan perhitungan dan pengukuran signal level kondisi penghalang 2 dinding

Dari gambar 1,2, dan 3 terlihat bahwa hasil pengukuran lebih baik dibandingkan dengan hasil perhitungan. Itu disebabkan oleh perhitungan yang di asumsikan menggunakan nilai koefisien transmisi dinding sebesar 0,3 dan koefisien. Dimana untuk koefisen dinding maupun lantai belum ada nilai pasti untuk mengukur $A P$ yang digunakan. Hal ini menyebabkan hasil perhitungan masih kurang tepat.

\section{KESIMPULAN}

Hasil perhitungan dan pengukuran signal level, di beberapa titik pengukuran memperlihatkan perbedaan angka yang 
mengakibatkan selisih pada hasil perbandingan tersebut, kondisi ini disebabkan oleh model propagasi indoor yang sifatnya memprediksikan, sehingga kondisi lingkungan menjadi salah satu faktor yang mempengaruhi hasil pengukuran tersebut. Untuk nilai signal level pengukuran tertinggi yang diperoleh adalah sekitar $-49 \mathrm{dBm}$, sedangkan signal level terendah adalah sekitar $-88 \mathrm{dBm}$.

Nilai QoS yang didapatkan pada setiap lantai di gedung B Rumah Sakit Kapal Kabupaten Badung berupa packet loss, delay, jitter, dan throughput dengan menggunakan 5 situs yaitu blogspot, kompas, youtube, google, dan facebook. Rata-rata nilai packet loss pada setiap situs sangat bagus di mana rata-rata persentase packet loss tidak lebih dari $3 \%$, dan ratarata dari nilai delay tidak lebih dari 100ms yang di mana standarisasi nilai QoS menyatakan sangat bagus. Pada nilai jitter didapatkan rata-rata jitter sebesar 0,040 ms, sehingga dalam kategori degradasi termasuk dalam kategori sangat bagus ( $0 \mathrm{~s} / \mathrm{d} 75 \mathrm{~ms})$.Pada throughput didapatkan nilai rata-rata sebesar 4,8 Mbps. Sehingga Qualitas dari setiap situs tersebut terdegradasi bagus. Sehingga kualitas jaringan dikatakan baik.

\section{DAFTAR PUSTAKA}

[1]. Feryawan, A. Analisis Karakteristik Propagasi Indoor WLAN IEEE 802.11n Untuk Lingkungan Laboratorium Jurusan Teknik Elektro Universitas Udayana. Skripsi. Badung : Universitas Udayana. 2013.

[2]. Agung Indra Prasetya, AAN, N.Gunantara, Sudiarta, P.K..2017. Analisis Propagasi Indoor WLAN 802.11g pada Gedung Diskominfo Kabupaten Badung. E-Journal SPEKTRUM Vol. 4, No.2 Desember 2017.

[3] Singh, J. Quality of Service in Wireless LAN Using OPNET Modeler. Patiala: Thapar University. 2009.

[4] N. Gunantara and G. Hendrantoro: Multi-Objective Cross-Layer Optimization with Pareto Method for Relay Selection in Multihop Wireless Ad hoc Networks, WSEAS Transaction on Communications, Vol. 12, Issue 3, 2013.

[5]. Riki Gunawan, Linawati, N.Gunantara, 2015. Performansi WLAN Kantor Pusat
Pemerintahan Kabupaten Badung. EJournal SPEKTRUM Vol. 14, No.2 Desember 2015.

[6]. Kurnia P,Kartika, Budi Santoso T,Adi Siswandari.2010. Skripsi . Optimasi Penataan Sistem Wi-Fi di PENS-ITS dengan Menggunakan Metode Algoritma Generator. 2010.

[7]. https://www.ubnt.com/products/\#unifi, diakses tanggal 30 oktober 2018.

[8]www.ekahau.com/products/hea tmapper/faq/, diakses tanggal 24 oktober 2018. 